\title{
Dor crônica na Atenção Primária à Saúde: a assistência integral aos usuários
}

\author{
Matheus Alvarenga
}

\section{Resumo}

De acordo com a International Association for the Study of Pain, dor é uma sensação ou experiência emocional desagradável, associada com dano tecidual real ou potencial. É classificada em aguda ou crônica quando tem duração inferior ou superior a 30 dias. Segundo a portaria $\mathrm{n}^{\circ} 1083$ de 2012, lançada pelo Ministério da Saúde, o Protocolo Clínico e de Diretrizes Terapêuticas da Dor Crônica, inexistem dados disponíveis no Brasil sobre a prevalência de dor crônica. No entanto, podemos perceber uma alta procura por atendimento relacionada a queixas osteoarticulares na Atenção Primária (APS). O caderno de Atenção Básica de Demanda Espontânea sugere que o atendimento aos usuários com dor crônica na APS seja realizado com o apoio dos profissionais do Núcleo de Apoio a Saúde da Família (NASF), pois o cuidado multiprofissional e interdisciplinar é potente para agregar recursos e contribuir para intervenções com maior resolutividade para o usuário, além de, capacitar as equipes de referência (MS, 2013). Descrever a experiência do grupo da Dor realizado em uma Unidade de Saúde. Relato de experiência. O grupo possui 70 usuários, de ambos os sexos, divididos em duas turmas quinzenais. São direcionados para o grupo por encaminhamento interno pelas equipes de saúde da Unidade. O critério para participação no grupo da Dor é: ter dor a mais de três meses, sem resposta terapêutica às intervenções da equipe de referência. Os usuários que atualmente participam do grupo tem entre 40 e 80 anos, sendo a maioria do sexo feminino. A atividade ocorre na Clínica da Família Felippe Cardoso, localizada no município do Rio de Janeiro. Iniciado em 2011, o grupo atualmente é coordenado pelo fisioterapeuta do NASF e pela enfermeira residente da Unidade, ocorre todas as segundas das $14 \mathrm{~h}$ às $17 \mathrm{~h}$. Ao longo das três horas há a realização de exercícios, nas quais os usuários são estimulados a perceber suas estruturas corporais e a importância do autocuidado para a manutenção de suas funcionalidades. Em um segundo momento, há a formação de uma roda para dar as boas vindas aos novos integrantes, e aqueles que já fizeram parte dos encontros anteriores falam a respeito do estado de saúde antes e após a entrado no grupo. Posteriormente, há a discussão de temas de saúde escolhidos previamente pelos usuários. Dentre eles: estrutura corporal, chikungunya, alimentos com propriedades anti-inflamatórias, risco de queda, uso de compressas quentes e frias. Ao final do encontro realizamos exercícios com bozu, cama elástica ebola suíça para estimular o equilíbrio e a socialização através de atividades lúdicas. Sabe-se que mesmo com o crescimento da cobertura da APS no Brasil, as práticas em saúde estão focadas nas intervenções medicamentosas e nos encaminhamentos para os serviços especializados. Dessa forma, entendemos que APS é um modelo de atenção potente na desmedicalização do atendimento aos usuários com dor crônica. Por ter como princípios o cuidado longitudinal e integral à saúde, além de proporcionar um cuidado multiprofissional aos usuários o grupo atua como uma ferramenta excelente para aplicabilidade destes princípios e construção de espaços coletivos de autocuidado.

Descritores: Dor Crônica, Atenção Primária à Saúde, Grupos. 